tion (here the 400 year early Holocene control climate before the perturbation; Fig. 1a) are statistically different, by comparing the variance and average. Subsequently, we separated cold and warm anomalies that are significant at the $99 \%$ level (Fig. $1 \mathrm{~b})$. For the grid-cells with significant cold and/or warm temperature anomalies, we calculated the following properties: the duration of the longest anomaly, the maximum 31-year mean temperature anomaly and the timing of the onset of the longest anomaly relative to the freshwater forcing (Fig. 1).

Applying this method on the separate ensemble members generates a climate response that also includes anomalous data points resulting from natural climate variability. Since we are interested in the temperature anomaly that is forced by the lake drainage, we average the output properties (magnitude, timing and duration) of the 10 ensemble members and mask grid-cells that do not show a significant anomalous response in each ensemble member. Subsequently, we generate anomaly maps for each of the properties. In contrast to many studies that aim to derive the externally forced climate signal (e.g., Stott et al., 2000), we do not first average the ensemble members and then perform the statistical test. The reasoning behind this is that we are interested in the signal that could be registered in climate proxy archives. This signal is comparable to the climate signal of a single ensemble member and different from the artificially enhanced signal of the ensemble average. We then average the properties in the ensemble members and filter out grid-cells that do not show a climate response in each of the ensemble members to obtain the robust response. This step is reasonable because all ensemble members showed a similar climate evolution.

\section{Timing, duration and magnitude}

Figure 2 shows the results of this analysis for the cold response in the DJF season. The first striking feature is that the cold anomaly is concentrated in the northern hemisphere, especially Greenland, the North Atlantic area and its eastern coastline. The Arctic Ocean and the Mediterranean Sea area are affected. A robust cooling response is also present in the Asian subtropical regions around $30^{\circ} \mathrm{N}$. Large variations in magnitude are evident, and the largest anomalies are north of Iceland and near Spitsbergen (Fig. 2a). Furthermore, time-lags in the onset of the event are present in the order of decades (Fig. 2b). Interestingly, the cold response in Greenland emerges ca. 40 years after the freshwater forcing. The duration of the event exhibits geographical variation as well, with the longest duration in the North Atlantic area and gradually decreasing towards the limits of the impact (Fig. $2 \mathrm{c}$ ). In the remaining areas where a response is simulated, the duration is in the order of decades, which strongly reduces the probability of being recorded. Moreover, applying the same analysis on the cold response in the June-July-August season provides insight into seasonal differences in the response. Focusing on the warm response provides information on the behavior of the bipolar seesaw and possible warm overshoots following an initial cooling (Wiersma et al., 2008).

To summarize, the method presented here is an improvement on the traditional analysis of climate modeling results and facilitates model-data comparison for several reasons. First, the method provides information on geographical variation in timing, duration and magnitude of abrupt climate events, which can serve as a framework for proxy-data interpretation. Second, proxy-based climate reconstructions can be compared directly to the modeling output, since the latter contains decadalscale information comparable to proxy records. Third, the results can be used to indicate areas where the event is expected to be registered in proxy records, providing clues about where to look for a specific climate response.

\section{References}

Alley, R.B., Mayewski, P.A., Sowers, T., Stuiver, M., Taylor, K.C. and Clark, P.U., 1997: Holocene Climatic Instability - a Prominent, Widespread Event 8200 Yr Ago, Geology, 25: 483-486.

Kobashi, T., Severinghaus, J.P., Brook, E.J., Barnola, J.-M. and Grachev, A.M., 2007: Precise timing and characterization of abrupt climate change 8200 years ago from air trapped in polar ice, Quaternary Science Reviews, 26: 1212-1222.

Thomas, E.R., Wolff, E.W., Mulvaney, R., Steffensen, J.P., Johnsen, S.J., Arrowsmith, C., White, J.W.C., Vaughn, B. and Popp, T., 2007: The $8.2 \mathrm{ka}$ event from Greenland ice cores, Quaternary Science Reviews, 26: 70-81.

Wiersma, A.P., Renssen, H., Goosse, H. and Fichefet, T., 2006: Evaluation of different freshwater forcing scenarios for the $8.2 \mathrm{ka}$ BP event in a coupled climate model, Climate Dynamics, 27: 831-849.

Wiersma, A.P., Roche, D.M. and Renssen, H., 2008: Fingerprinting the $8.2 \mathrm{ka}$ BP event climate response in a coupled climate model. In: Wiersma, A.P., Character and causes of the 8.2 ka climate event, comparing coupled climate model results and palaeodimate reconstructions, PhD Thesis, VU University Amsterdam, The Netherlands.

For full references please consult:

www.pages-igbp.org/products/newsletter/ref2008_2.html

\title{
PMIP2 climate model-proxy data intercomparisons for the LGM
}

\author{
Bette L. Otto-Bliesner and Esther Brady \\ National Center for Atmospheric Research, Boulder, USA; ottobli@ucar.edu
}

Climate models may perform equally well for simulating the present-day and $20^{\text {th }}$ century climates, yet produce very different responses to likely changes in forcing (such as greenhouse gases and insolation) in the future. Therefore, it is important to compare current state-of-the-art climate model simulations of past climates against the benchmarks of paleo-observations. The Paleoclimate Modelling Intercomparison Project (PMIP) is a long-standing initiative endorsed by PAGES and the World Climate Research Programme JSC/ CLIVAR Working Group on Coupled Models (WGCM). It provides for coordination of paleoclimate modeling activities on the mechanisms of climate change, the identification of key feedbacks operating in the climate system, and on the capability of climate models to reproduce climates that are different from modern.

PMIP initially focused on two periods, the Last Glacial Maximum (LGM; ca. 21 cal kyr BP) and the mid-Holocene $(\mathrm{MH}$; ca. $6 \mathrm{cal} \mathrm{kyr} \mathrm{BP).} \mathrm{The} \mathrm{experiments} \mathrm{were} \mathrm{de-}$ signed to examine the climate response to Milankovitch orbital forcings for the $\mathrm{MH}$ and the presence of large ice sheets and low greenhouse gas (GHG) concentrations for the LGM. Seventeen modeling groups participated in simulations of these time periods with atmosphere-only models (PMIP1), and twelve groups in the second phase of the project (PMIP2) using oceanatmosphere or ocean-atmosphere-vegetation models. With the incorporation of coupled atmosphere-ocean-sea ice models into PMIP2, new comparisons to proxy data can now be used in evaluating the capabilities of current climate models to simulate climate conditions different than present. Here, we describe two such comparisons of the PMIP2 LGM simulations to glacial proxy data: deep-ocean tempera- 
tures and salinities in the Atlantic Ocean, and sea ice extent around Antarctica.

\section{PMIP2 LGM simulations}

Six international modeling groups have contributed PMIP2 simulations for the LGM: CCSM (the National Center for Atmospheric Research CCSM3 model), HadCM (the UK Met Office HadCM3M2 model), FGOALS (the LASG/Institute of Atmospheric Physics FGOALs-g1.0 model), IPSL (the Institut Pierre Simon Laplace IPSLCM4-V1-MR model), MIROC (the CCSR/ NIES/FRCGC MIROC3.2.2 medres model), and ECBilt-CLIO (the KNMI ECBilt/Louvainla-Neuve CLIO intermediate complexity model)-models also used for the IPCC AR4 simulations of future climate change. For the PMIP2 LGM simulations (Braconnot et al., 2007), all of the models used the ICE-5G reconstruction of LGM continental ice sheets (Peltier, 2004), the same change from pre-industrial levels of atmospheric concentrations of carbon dioxide $\left(\mathrm{CO}_{2}\right)$, methane $\left(\mathrm{CH}_{4}\right)$, and nitrous oxide $\left(\mathrm{N}_{2} \mathrm{O}\right)$ based on the ice core records (Fluckiger et al., 1999; Dallenbach et al., 2000; Monnin et al., 2001), the specification of additional land due to a lowering of sea level, and the change to insolation resulting from a slightly different orbit of the Earth. The presence of extensive glacial ice sheets accounts for over half of the total radiative forcing of the troposphere (Hewitt and Mitchell, 1997), and the lowering of GHG concentrations (primarily the $\mathrm{CO}_{2}$ ) accounts for most of the remaining radiative forcing (Otto-Bliesner et al., 2006), with small contributions from the additional land and insolation changes.

\section{Atlantic deep-ocean temperatures and salinities}

Pore fluid measurements of the chloride concentration and the oxygen isotopic composition from Ocean Drilling Program (ODP) cores in the Atlantic have allowed the simultaneous reconstruction of salinity and temperature of the deep ocean for the LGM (Fig. 1) (Adkins et al., 2002). For modern, the core top samples indicate the presence of warm, salty North Atlantic Deep Water at great depths for latitudes north of $\sim 40^{\circ} \mathrm{N}$, with the colder and somewhat fresher Antarctic Bottom Water dominating south of this latitude. For LGM, these cores indicate that the Southern Ocean deep water extended its influence far into the North Atlantic. LGM Atlantic deep waters were much colder and saltier than modern day. Additionally, deep ocean potential temperatures $(\theta)$ were relatively homogenous over the north-south extent of the Atlantic, com-

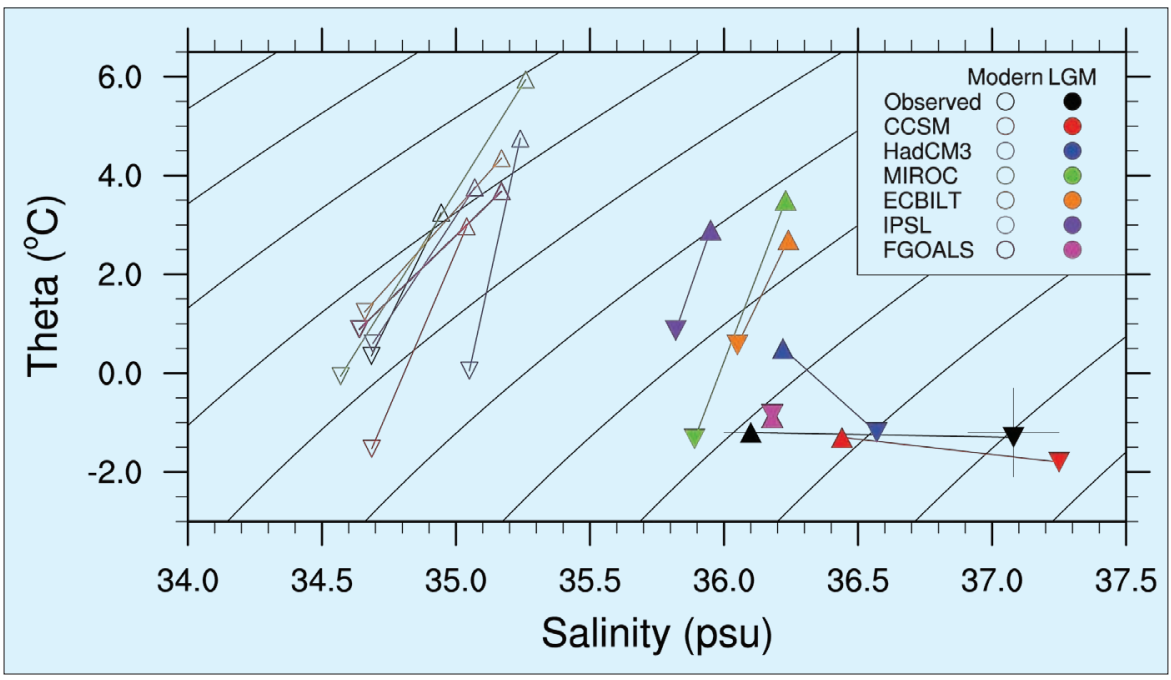

Figure 1: Theta (potential temperature) and salinity for modern (open symbols) and LGM (filled symbols) estimated from data (black symbols with error bars) at ODP sites (Adkins et al., 2002) and predicted by PMIP2 models. Site $981(\Delta)$ is located in the North Atlantic (Feni Drift, 55 N, 15 W, $2184 \mathrm{~m}$ ). Site $1093(\nabla)$ is located in the South Atlantic (Shona Rise, $50^{\circ} \mathrm{S}, 6^{\circ} \mathrm{E}, 3626 \mathrm{~m}$ ). Only CCSM included a 1 psu adjustment of ocean salinity at initialization to account for fresh water frozen into LGM ice sheets; predicted salinities for the other models have been adjusted to allow comparison.

pared to modern data. The data also suggest a significant north-south deep ocean salinity gradient during the LGM in the Atlantic, with the deep Southern Ocean much saltier than the North Atlantic.

The PMIP2 models can be used to simulate the three-dimensional temperature and salinity structure of the oceans. Model-ODP comparisons show that the models reproduce the modern deep ocean temperature-salinity structure in the Atlantic basin relatively well (Fig. 1). They simulate warmer and saltier deep waters at Feni Drift in the North Atlantic than at Shona Rise in the Atlantic sector of the Southern Ocean, with deep ocean density gradients mainly due to the temperature difference. Greater differences between models occur for the LGM simulations. Three of the models simulate a very cold and relatively homogeneous temperature structure from north to south in the Atlantic basin, with CCSM also simulating the observed large north-south salinity differences during the LGM. The other three models also simulate colder LGM deep waters and somewhat greater salinity increases in the Southern Ocean than the North Atlantic as compared to modern but retain the temperature-salinity structure of the modern simulation.

\section{Southern hemisphere sea ice}

Planktic foraminiferal estimates of sea surface temperature and abundances of diatoms and radiolarians preserved in deepsea sediments in the Southern Ocean have been utilized for reconstructing LGM sea ice extent around Antarctica. Increasing abundances of taxa that show a strong correspondence to sea ice or open ocean have been used to estimate statistically the number of months per year of sea ice cover (Gersonde et al., 2005; Crosta, 2007). The diatom records confirm the presence of extensive sea ice around Antarctica during LGM winters, similar to the reconstruction of CLIMAP (CLIMAP project members, 1981) but argue for a more restricted extent during LGM summers (Fig. 2). The diatom-reconstructed LGM summer seaice margin around Antarctica extended far northward to $\sim 55-60^{\circ} \mathrm{S}$ in the Atlantic, while in the Indian Ocean sector, the extent was similar to modern.

The climate models used for PMIP2 predict the thermodynamics and dynamics of sea ice with sea ice models of varying complexities. All the models simulate an expansion of sea ice at LGM compared to modern, with greater expansion in the Atlantic sector than the Pacific sector. Overall, the models agree with the data on winter LGM sea ice extent in the Pacific sector but only two models extend the sea ice as far northward as the data in the Atlantic sector. The model simulations of summer sea ice extent are much less consistent. Three of the models simulate LGM summer sea ice extent comparable to modern extent in the Southern Ocean, while the other three models simulate much more expansion of LGM summer sea ice. The asymmetry of LGM summer sea ice extent between the Atlantic and Indian Ocean sectors, as indicated by the data, is simulated poorly by all the models. The FGOALS model simulates the greatest sea ice extent during the LGM, with relatively small seasonal variation.

\section{Implications}

It has been shown that the response of the coupled climate system to changes in GHG forcing is dependent on the simulation of sea ice physics and strong sea ice 


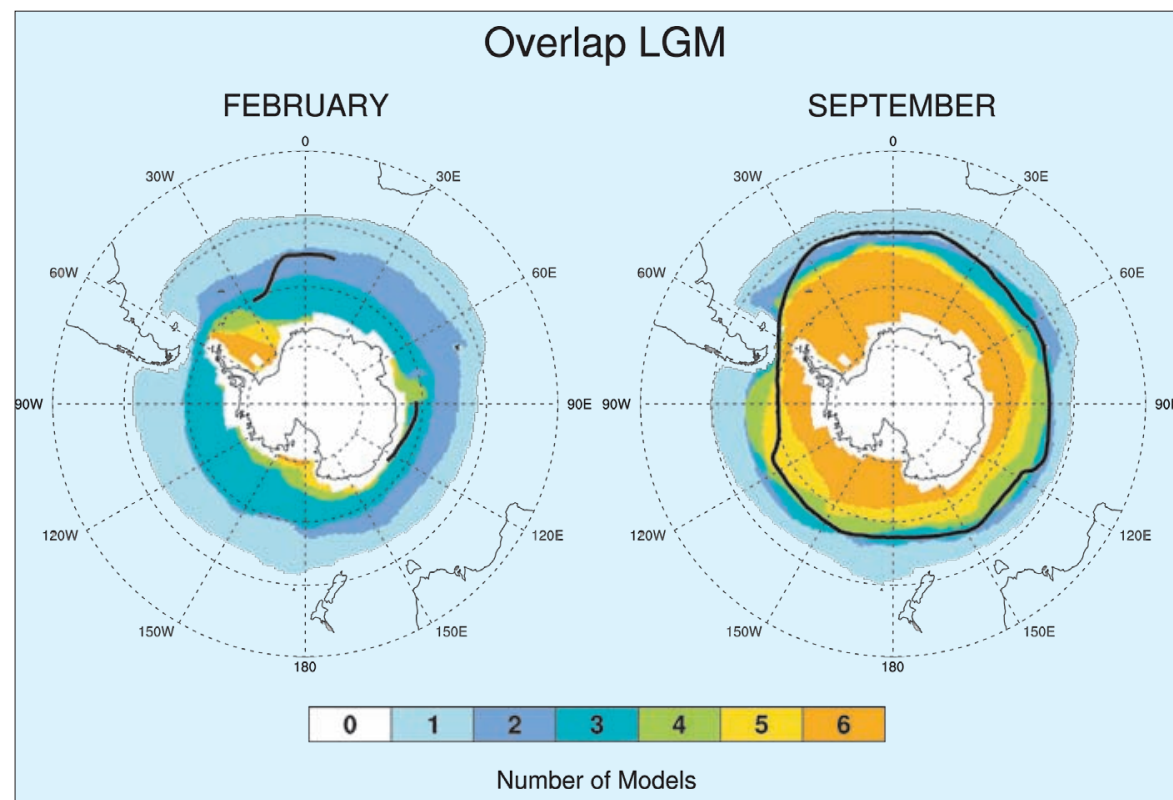

Figure 2: LGM sea ice distribution in the southern hemisphere simulated by PMIP2 models for February and September. For each grid cell, the figure indicates the number of models that simulate at least $15 \%$ of the area covered by sea ice. The proxy reconstructions of sea-ice edge (black lines) are from Gersonde et al. (2005)

feedbacks (Holland et al., 2001). This complexity is also highlighted by these PMIP2 results, where models show a large range of sea ice and associated ocean circulation responses to LGM forcing. Climate model simulations combined with proxy reconstructions have shown that LGM sea ice and ocean stratification can provide additional constraints on interpretation of the LGM Atlantic meridional overturning (Shin et al., 2003; Otto-Bliesner et al., 2007). LGM sea ice extent has been shown to be important in modulating the atmosphereocean interactions and water mass formation in the subpolar North Atlantic. The cold, salty Antarctic bottom waters at LGM form in coastal leads and just equatorward of permanent sea ice cover, due to brine rejection during sea ice production. Additionally, the suppression of air-sea gas exchange due to glacial sea ice expansion in the Southern Ocean has been suggested to play a possible role in regulating past atmospheric $\mathrm{CO}_{2}$ (Morales Maqueda and Rahmstorf, 2002; Stephens and Keeling, 2000).

Further information on the models discussed can be found at www.pages-igbp.org/products/newsletter/ref2008_2.html. Details on PMIP2 can be found at http://pmip2.Isce.ipsl.fr

\section{Acknowledgements}

We acknowledge the international modeling groups for providing their data for analysis, and the Laboratoire des Sciences du Climat et de l'Environnement for collecting and archiving the model data. The PMIP2/MOTIF Data Archive is supported by CEA, CNRS, the EU project MOTIF and the Programme National d'Etude de la Dynamique du Climat. Funding for NCAR and this research was provided by NSF.

\section{References}

Adkins, J.F., Mclntyre, K. and Schrag, D.P., 2002: The salinity, temperature, and $\delta^{18} 0$ of the glacial deep ocean, Science, 298: 1769-1773.

Braconnot, P. et al., 2007: Results of the PMIP2 coupled simulations of the mid-Holocene and Last Glacial Maximum. Part 1: experiments and large scale features, Climate of the Past, 3: 261-277.

Crosta, X., 2007: Late Quaternary Antarctic sea-ice history: Evidence from deep-sea sediments, PAGES News, 15(2): 13-14.

Gersonde, R, Crosta, X, Abelmann, A and Armand, L, 2005. Seasurface temperature and sea ice distribution of the Southern Ocean at the EPILOG Last Glacial Maximum - a circum-Antarctic view based on siliceous microfossil records, Quaternary Science Reviews, 24: 869-896.

Otto-Bliesner, B.L., Hewitt, C.D., Marchitto, T.M., Brady, E., Abe-Ouchi, A., Crucifix, M., Murakami, S. and Weber, S.L., 2007: Last Glacial Maximum ocean thermohaline circulation: PMIP2model intercomparisons and data constraints, Geophysical Research Letters, 34: L12706, doi:10.1029/2007GL029475.

For full references please consult:

www.pages-igbp.org/products/newsletter/ref2008_2.html

\section{Are paleo-proxy data helpful for constraining future climate change?}

Thomas Schneider von Deimling, H. Held, A. Ganopolski and S. Rahmstorf

Potsdam Institute for Climate Impact Research, Germany; schneider@pik-potsdam.de

How sensitive is our climate system to $\mathrm{CO}_{2}$ ? This is a key issue in a world of rising greenhouse gas concentrations. Estimating the temperature sensitivity of the Earth to changes in atmospheric $\mathrm{CO}_{2}$ has therefore been the subject of intensive research. Yet, uncertainty in our knowledge of this sensitivity is still large-as expressed by the broad $2-4.5^{\circ} \mathrm{C}$ range of climate sensitivity $\left(\Delta \mathrm{T}_{2 \mathrm{x}}\right)$ estimates (Meehl et al., 2007). Commonly $\Delta \mathrm{T}_{2 \mathrm{x}}$ is defined as the equilibrium global-mean temperature change for doubling the pre-industrial $\mathrm{CO}_{2}$ concentration. The direct radiative effect is a warming by $1^{\circ} \mathrm{C}$ but what makes the total warming uncertain is the strength of the fast climatic feedbacks - mainly ice-albedo, water vapor, lapse rate and cloud feedback. Here, we discuss how paleo-data can be used to reduce uncertainty in the range of $\Delta \mathrm{T}_{2 \mathrm{x}}$.

One way to compute climate sensitivity is to use climate models that calculate the feedbacks and thus $\Delta \mathrm{T}_{2 \times}$. Another ap- proach is to use the observed response of the climate system to constrain climate sensitivity. Studies using the climate signal provided by the instrumental record of the past 100-150 years were unable to rule out $\Delta \mathrm{T}_{2 \mathrm{x}}$ values above the IPCC range (Meehl et al., 2007). Unless we wait for the climate change signal to become much stronger, it will not be possible to greatly reduce uncertainty in $\Delta T_{2 x}$ in this way. A way out of this dilemma may be the use of paleo-data, which contain information on how sensitively the climate system has responded in the past to a radiative perturbation.

The three critical conditions for the success of this approach are: (1) a sufficiently large climate response in order to separate the signal from climatic noise, and sufficiently accurate data describing both (2) the climate change and (3) the forcing of this climate change. A promising candidate is the climate of the Last Glacial Maximum (LGM; 21 kyr BP), a time period that was on global average $4-7{ }^{\circ} \mathrm{C}$ colder than today (Schneider von Deimling et al., 2006a) with an abundance of good data on the forcing and the temperature distribution.

The observed response, seen through past climate changes, can be used in two ways for inferring $\Delta \mathrm{T}_{2 \mathrm{x}}$ :

(1) The ratio of past temperature change to forcing is estimated based on data and is then taken as a measure for the temperature response to doubling of $\mathrm{CO}_{2}$ (paleo-calibration, Covey et al., 1996). This approach assumes that the strength of the climate feedbacks inferred from the past can be taken as a direct measure for $\Delta T_{2 x^{*}}$ As the past is not a perfect analog for the future (e.g., the spatially inhomogeneous glacial forcing differs from the homogeneous $2 \mathrm{xCO}_{2}$ forcing), this assumption may be questionable.

(2) Using paleo-data in conjunction with climate models to constrain model 